\title{
ON PERSISTENCE AND INVADING SPECIES IN ECOLOGICAL DYNAMICS
}

\author{
E. SANCHEZ-PALENCIA AND J.-P. FRANÇOISE*
}

\begin{abstract}
The general problem of persistence of species, amounts to define interactions between them ensuring the survival of all the species initially present in the system. It appears that several relevant persistence schemes induce "forbidden sets" of zero measure for topological reasons. These peculiarities (without practical consequences) are nevertheless not consistent with certain mathematical definitions of persistence, which are too much restrictive. We come back to definitions of McGehee - Armstrong and their celebrated counter-example to the so-called "competitive exclusion principle". We develop these concepts in relation with invasion properties of the species in a rather practical and computational framework. Several examples of communities exhibiting persistence without internal rest point (which necessarily exists according to strict persistence definitions) are given, with explicit description of the attractors, forbidden sets and invasion properties. Mechanisms of contamination of these properties (based on elementary cartesian product and structural stability) are given, showing the widespreading nature of these schemes.
\end{abstract}

Mathematics subject classification (2020): Primary 34C60; Secondary 92D40.

Keywords and phrases: Ecological dynamics, persistence, invading species, attractor blocks.

\section{REFERENCES}

[1] F. BRAuner And C. CASTILlo-Chavez, Mathematical models in population biology and epidemiology, Springer (2012).

[2] C. CONLEY AND R. EASTON, Isolated invariant sets and isolating blocks, Transactions AMS 158, p. 35-61 (1971).

[3] Jean-Pierre Françoise, Oscillations en biologie (French) [Oscillations in biology], Analyse qualitative et modèles [Qualitative analysis and models], Mathématiques \& Applications (Berlin) [Mathematics \& Applications], 46, Springer-Verlag, Berlin, (2005).

[4] G. F. GAuse, Vérifications expérimentales de la théorie mathématique de la lutte pour la vie, Hermann, Paris (1935).

[5] Morris W. Hirsch, Stephen Smale, Robert L. Devaney, Differential equations, dynamical systems, and an introduction to chaos, Third edition. Elsevier/Academic Press, Amsterdam, (2013).

[6] J. Hofbauer And K. Sigmund, The theory of Evolution and Dynamical Systems, London Math. Soc. Student Texts 7, Cambridge University Press (1988).

[7] S. B. Hsu, S. P. Hubblell AND P. WAltman, A contribution to the theory of competing predators, Ecological Monographs 48, p. 337-349 (1978).

[8] S. B. Hsu, S. P. Hubblell and P. Waltman, Competing predators, SiAM J Appl Math 35, p. 617-625 (1978).

[9] V. Hutson, K. Schmitt, Permanence and the dynamics of biological systems, Mathematical Biosciences 111, p. 1-71 (1992).

[10] G. KirLIngER, Permanence of some ecological systems with several predators and one prey species, Jour Mathematical Biol 26, p. 217-232 (1988).

[11] A. L. KocH, Competition coexistence of two predators utilizing the same prey under constant environment conditions, Jour Theor Biol 44, p. 387-395 (1974). 
[12] Ph. Lherminier, E. SAnChez-Palencia, Remarks and examples on transient processes and attractors in biological evolution, Elec. Jour. Diff. Equat. Conference 22, p. 63-77 (2015).

[13] C. Lobry, Modèles déterministes en Dynamique des Populations, Ecole CIMPA Saint Louis du Sénégal (2001).

[14] K. S. MCCANn, The diversity - stability debate, Nature 405, p. 228-230 (11 may 2000).

[15] R. MCGehee, R. A. ARMSTRONG Some mathematical problems concerning the ecological principle of competetive exclusion, Journal of Differential Equations 23, p. 30-52 (1977).

[16] J. MiLnOR, Topology from the differential viewpoint, The University Press of Virginia, Charlottesville (1965).

[17] S. Muratori and S. Rinaldi, Remarks on competitive coexistence, SIAM J. Appl. Math. 49, p, 1462-1472 (1989).

[18] E. SAncheZ-PALEncia, J.-P. FrançOISE, Structural stability and emergence of biodiversity, Acta Biotheoretica 61 (2) p. 397-412 (2013).

[19] E. SAnCheZ-PALEnCIA, J.-P. FRAnÇOISE, Constrained evolution processes and emergence of organized diversity, Math Meth Applied Sci 39 (1), p. 104-133 (2016).

[20] E. SAnCheZ-PALEnCIA, J.-P. FRAnÇOISE, Topological remarks and new examples of persistance in biological dynamics, Discr Cont Dyn Syst series S, 12 (6), p. 1775-1789 (2019).

[21] E. Sanchez-Palencia, J.-P. Françoise, New Schemes of Dynamic Preservation of Diversity: Remarks on Stability and Topology, Acta Biotheoretica 68, p. 157-169 (2020).

[22] S. J. SCHREIBER, Criteria for $C^{r}$ robust permanence, Journal of Differential Equations 162, p. 400426 (2000).

[23] Hal. L. Smith And H. R. Thieme, Dynamical systems and population persistence, Graduate Studies in Mathematics, vol. 111, Amer. Math. Soc. (2011).

[24] Weishi Liu, Dongmei Xiao And Yingfei Yi, Relaxation oscillations in a class of predator - prey systems, Journal of Differential Equations 188, p. 306-331 (2003).

[25] V. Volterra, Variazioni e fluttuaziono del numero di individui in specie animali conviventi, Mem. Accad. Lincei 2, p. 31-113 (1926). 